\title{
GÊNERO, RAÇA E ESCOLARIZAÇÃO NA BAHIA E NO RIO DE JANEIRO
}

\author{
ALCEU RAVANELLO FERRARO \\ Professor titular aposentado do Departamento de Estudos Básicos \\ da Faculdade de Educação da Universidade Federal do Rio Grande do Sul \\ alceu.ferraro@pq.cnpq.br
}

\begin{abstract}
RESUMO
Este artigo aborda a relação entre gênero, cor/raça e escolarização nos estados da Bahia e do Rio de Janeiro com base em microdados do Censo 2000. Pesquisa a trajetória da média de anos de estudo de homens brancos, homens negros, mulheres brancas e mulheres negras através das gerações. Os resultados evidenciam a reprodução das desigualdades regionais quanto à escolarização; confirmam, para ambos os sexos e estados, a reprodução, através das gerações, das desigualdades educacionais que desfavorecem a população negra; evidenciam, tanto para brancos/as como para negros/as, uma inversão na relação entre gênero e educação nos dois estados. O desafio para a pesquisa é traçar no tempo a trajetória do movimento que levou as mulheres da condição de inferioridade à de superioridade em relação aos homens quanto à escolarização, tanto entre brancos/as quanto entre negros/as e em ambos os estados pesquisados. GÊNERO - RAÇA - ESCOLARIZAÇÃO - IGUALDADE DE OPORTUNIDADES
\end{abstract}

\section{ABSTRACT}

GENDER, RACE AND SCHOOLING IN BAHIA AND RIO DE JANEIRO. Based on microdata from the Census of 2000, this article approaches the relation between gender, skin color/race and schooling in the states of Bahia and Rio de Janeiro. It examines the course of the average years of study of white men, black men, white women, and black women throughout the generations. Its results make evident the reproduction of regional inequalities regarding schooling throughout the generations; they confirm the reproduction of educational inequalities to the prejudice of the black population throughout the generations for both genders and states; they make evident an inversion of the relation between gender and education in both states, both for male and female whites and blacks. The challenge posed by the research is to sketch the course of the movement

Otrabalho é o primeiro produto do projeto Gênero, Cor/Raça e Escolarização no Brasil: Traçando a Trajetória da Relação, com apoio do Conselho Nacional de Desenvolvimento Científico e Tecnológico - CNPq - para o período de março/2007 a fevereiro/20 I 0. Apresentado na 30 Reunião Anual da Associação Nacional de Pós-Graduação e Pesquisa em Educação - Anped -, no Grupo de Trabalho Sociologia da Educação, de 7 a 10 de outubro de 2007, foi posteriormente revisto para publicação como artigo. 
in time that resulted in the change of the female condition of inferiority in schooling to that of superiority in relation to men, both among female and male whites and among female and male blacks in both states.

GENDER - RACE - SCHOOLING - EQUAL EDUCATION

Do ponto de vista teórico, são cada vez mais frequentes e enfáticas, pelo menos desde os anos 1980, as manifestações em favor de que, no estudo da educação, se busque articular principalmente as dimensões de gênero, étnico-raciais e de classe social. Parece ser menos frequente a referência à perspectiva regional.

É o caso, por exemplo, de Michel W. Apple (1987, p. I 2), quando afirma que "simplesmente não podemos entender o que está acontecendo ao ensino e ao currículo sem colocá-los em uma moldura teórica que integre classe (e o processo de proletarização que a acompanha) e gênero." Mariano F. Enguita ( 1996$),$ em seu artigo "Os resultados desiguais das políticas igualitárias", focaliza a ação de classe, gênero e etnia na educação. Vai no mesmo sentido a conclusão de Diane Reay ( | 99 | , p. |8|), em seu estudo sobre as intersecções de gênero, raça e classe na escola primária: "Qualquer tentativa de extrair orientações claras e precisas para uma política antissexista é complicada pela necessidade de se levarem em conta especificidades de raça e classe assim como de gênero." Na África do Sul pós-apartheid, uma das respostas mais significativas ao novo desafio tem sido a Investigação da Política de Educação Nacional, estabelecida dentro do movimento democrático, cujos

...princípios fundantes de não-racismo, não-sexismo, igualdade, democracia e ação afirmativa para corrigir desequilíbrios históricos atestam um compromisso com questões de natureza política e econômica que vão enfrentar a pobreza dos negros num ordenamento pós-apartheid. (Christie, Gordon, 1992, p.408-409)

Em relação ao Brasil, Hasenbalg ( 1995, p.359), em pesquisas realizadas nas regiões Norte, Nordeste e Sudeste, constatou "uma forte associação entre cor ou raça e status socioeconômico", o que, segundo ele, confirma o dito de que, no Brasil, a pobreza tem cor. A mesma associação entre cor e pobreza é encontrada em artigo sobre a luta secular dos quilombolas em Gorutuba, Minas Gerais. "Onde está o negro - diz a autora - está a pobreza no Brasil” (Athayde, 2006, p. I3). 
Quanto à pesquisa em educação no país, Fúlvia Rosemberg distinguiu-se pelas tentativas de análise da associação das dimensões gênero, raça e classe social com educação. Exemplos são os estudos sobre analfabetismo (Rosemberg, 1993; Rosemberg, Piza, 1995/1996) e educação infantil (Rosemberg, 1996). Ao que se saiba, o estudo em parceria com Piza, "Analfabetismo, gênero e raça no Brasil", foi a primeira tentativa aqui de uma abordagem da relação entre gênero, raça e analfabetismo na perspectiva de longo prazo, com base nos censos demográficos. As pesquisadoras registram o fato de se ter silenciado, em estudo da década anterior, sobre as proximidades e diferenças entre os sexos e as raças. Recorde-se ainda a discussão sobre a relação de classe, raça e gênero com a educação infantil, em que Rosenberg denuncia, por exemplo, "a desigualdade no custeio/qualidade que penaliza crianças pobres e negras de diferentes formas", inclusive aquela denominada pela autora "morte educacional anunciada" (Rosemberg, 1996, p.64).

Marília Pinto de Carvalho, em sua análise da trajetória de vida e da prática pedagógica da professora Aida, também levou em consideração classe, raça e gênero (Carvalho, 1999). O mesmo se diga do estudo "O fracasso escolar de meninos e meninas: articulações entre gênero e cor/raça", em que a autora, valendo-se de questionários e entrevistas em profundidade, trabalha com a hipótese de que, "pelo menos no âmbito da escola, a identidade racial de meninos e meninas seria construída tendo como referência não apenas características fenotípicas e status socioeconômico, mas também seu desempenho escolar" (Carvalho, 2004, p.247).

As observações de Kia Lilly Caldwell em seu estudo sobre gênero e raça no Brasil seguem a mesma linha. A autora observa que, desde o final dos anos 1970, mulheres inglesas, canadenses e norte-americanas não brancas "desafiaram modelos unitários de gênero e exigiram noções sobre 'ser mulher' que levassem em conta raça, etnia, classe e sexualidade" (Caldwell, 2002, p.92). Referindo-se a período mais recente, ela diz que "feministas brancas e negras analisaram os modos como as diferenças entre mulheres estão ligadas a estruturas maiores de desigualdade, particularmente as que resultam de práticas de discriminação racial" (p. 100).

Este estudo, na medida em que contrapõe homens brancos, homens negros, mulheres brancas e mulheres negras em sua relação com a educação escolar, coloca em foco a relação cruzada das variáveis sexo e cor/raça com 
educação. Faz isto, porém, confrontando duas situações bem distintas do ponto de vista regional: os estados da Bahia e do Rio de Janeiro.

\section{CONCEITUAÇÃO BÁSICA}

No que se refere à educação escolar, trabalha-se com o indicador "média de anos de estudo", calculado a partir da informação censitária sobre o número de anos de estudo concluídos com aprovação pelas pessoas recenseadas.

Os censos e as Pesquisa Nacional por Amostra de Domicílios - PNADs - perguntam sobre o sexo das pessoas, registrando masculino ou feminino. Vários censos - não todos - pesquisaram cor. O Censo 2000 perguntou sobre cor ou raça, registrando branca, preta, amarela, parda, indígena (IBGE, 2000). A opção aqui é por limitar a pesquisa à consideração das cores/raças branca, preta e parda, reunindo estas duas últimas na categoria cor/raça negra. Os censos indagam também sobre características educacionais, assim como sobre ocupação, ramo de atividade, rendimento etc.

Mas não há como imaginar os/as entrevistadores/as perguntando às pessoas sobre seu gênero, sua raça, sua classe social. Os censos investigam características manifestas da população, imediatamente perceptíveis, tais como sexo, cor, atividade, idade etc. São os/as pesquisadores/as que introduzem termos como gênero, raça, classe, geração, infância etc., que envolvem conceitos mais abstratos. Fazem isso com o intuito de problematizar ou de interpretar as relações dessas variáveis com a educação escolar.

Ao analisar uma tabela do censo que relacione sexo e/ou cor/raça com alfabetização ou qualquer outra característica educacional, o pesquisador poderá introduzir termos/conceitos como gênero, raça e/ou classe social. Se o fizer, será por entender que as eventuais desigualdades em termos de alfabetização, escolarização, letramento, matrícula etc. encontradas entre pessoas de sexo masculino e feminino, entre pessoas de cor/raça branca, preta, parda, entre filhos/as de trabalhadores e de empregadores decorrem não das diferenças físicas existentes entre essas categorias de pessoas, mas de relações sociais (de escravização, assalariamento, dominação, exclusão, preconceito, discriminação etc.) que se tenham estabelecido historicamente entre elas: entre homens e mulheres, entre pessoas brancas e negras, entre empregadores e assalariados, entre as diferentes regiões ou unidades da federação. 
Para a conceituação de gênero, parte-se da conhecida distinção feita por Linda Nicholson:

De um lado, o "gênero" foi desenvolvido e é sempre usado em oposição a "sexo", para descrever o que é socialmente construído em oposição ao que é biologicamente dado. Aqui, "gênero" é tipicamente pensado como referência a personalidade e comportamento, não ao corpo; "gênero" e "sexo" são, portanto, compreendidos como distintos. De outro lado, "gênero" tem sido cada vez mais usado como referência a qualquer construção social que tenha a ver com a distinção masculino/feminino, incluindo as construções que separam corpos "femininos" de corpos "masculinos". (Nicholson, 2000, p.9)

Mesmo que a autora se decida pelo segundo sentido, opta-se, aqui, pela utilização do termo no primeiro sentido, isto é, "em oposição a sexo, para descrever o que é socialmente construído em oposição ao que é biologicamente dado" - justamente o sentido rejeitado por Nicholson. Segue-se, neste ponto, o entendimento de Sylvia Walby quando define gênero na perspectiva das ciências sociais:

Representando o aspecto social das relações entre os sexos, gênero é um conceito que se distingue do conceito biológico de sexo. A questão de se, e até que ponto, os aspectos biológicos dos sexos são pertinentes à compreensão do gênero é popularmente controvertida, mas dentro das ciências sociais a questão é encarada, de maneira ampla, como resolvida - a organização social é o fator esmagadoramente preponderante. (Walby, 1996, p.332)

Pensa-se que esse uso do termo gênero permite trabalhar com a variável sexo - como utilizada habitualmente pelo Instituto Brasileiro de Geografia e Estatística - IBGE - em seus levantamentos, tanto censitários como amostrais - e que, ao mesmo tempo, a categoria analítica gênero pode ser introduzida, justamente para contraditar o determinismo biológico na explicação das desigualdades sociais e educacionais existentes entre homens e mulheres.

Quanto ao termo raça, a questão conceitual é complexa, por envolver também cor e etnia. No Brasil, no Censo 2000, as pessoas foram interrogadas 
sobre sua cor ou raça. Nos censos anteriores, quando o tema foi investigado, perguntou-se apenas sobre a cor.

O termo raça carrega ainda, em seu desabono, laivos das teorias racistas do século XIX. Merecem destaque a obra de Arthur de Gobineau (1983), Essays sur l'inegalité dês races humaines [Ensaio sobre as desigualdades das raças humanas], e a de Luis Gumplowicz, La lucha de razas [A luta das raças] publicada originalmente em I 882. Para Gobineau, a história humana não passa de uma grande toalha estendida sobre a terra, que tem nos séculos, em seu conjunto, os seus artesãos infatigáveis. $\bigcirc$ tecido, assim como não tem uma única cor, também não se compõe de uma única matéria. Segundo o autor:

As duas variedades inferiores da nossa espécie, a raça negra, a raça amarela, constituem o fundo grosseiro, o algodão e a lã, que as famílias secundárias da raça branca amaciam misturando-Ihes a sua seda, enquanto que o grupo ariano, ao fazer circular os filetes mais finos através das gerações enobrecidas, aplica à sua superfície, como em obra-prima ofuscante, seus arabescos de ouro e prata. (Gobineau, 1983, p.1.143)

Gumplowicz, que vê a história como um fenômeno da natureza, sustenta que "A luta das raças pelo domínio, pelo poder, a luta sob todas as suas formas, sob uma forma violenta ou latente e pacífica, é o princípio propulsor propriamente dito, a força motriz da história" (Gumplowicz, 1944, p.221, tradução nossa).

Após a Segunda Guerra Mundial o termo raça entrou em descrédito. Vários fatores contribuíram para isso, podendo-se destacar, de um lado, a reação contra a campanha eugênica norte-americana para criar uma raça superior (Black, 2003) e a reação contra o extermínio de judeus pelo nazismo, e, de outro, mudanças de enfoque no domínio científico. Ultimamente, o termo voltou a ser utilizado com força, especialmente em consequência do despertar da consciência negra, da luta contra o racismo e da emergência das políticas afirmativas relacionadas com a questão racial.

No caso do Brasil, quando se fala em cor e/ou raça, pensa-se principalmente na população negra ou afrodescendente e/ou na luta contra o racismo ou a favor da superação das desigualdades raciais em relação ao negro. Recorre-se ao termo etnia quando se pensa, por exemplo, nas múltiplas etnias indígenas, 
nos grupos populacionais de origem germânica, italiana, polonesa, sírio-libanesa etc., e inclusive nas diferenças internas dentro da própria cor/raça negra.

Para Sergio Costa (200 I), o conceito de raça teve uma carreira oscilante no Brasil. Até os anos 1930, o conceito tinha seus fundamentos na biologia e era utilizado para hierarquizar os diferentes segmentos da população. No período entre 1930 e 1970, assistiu-se ao mesmo tempo a uma perda de importância política do conceito e ao abandono por completo, no âmbito acadêmico, da ideia da existência biológica de raças entre os seres humanos. $\bigcirc$ que se seguiu, a partir dos anos 1970, com o conceito de raça é assim descrito pelo autor:

A partir dos anos 70, o conceito de raça através, entre outros, da influência da discussão norte-americana, ganha renovada importância política no Brasil, funcionando como instrumento de ruptura da homogeneidade construída simbolicamente pela política da mestiçagem como se se tratasse de dissociar os grupos socioculturais fundidos na simbologia da nação mestiça. Assim, o conceito de raça se transforma em instrumento de mobilização política, em construção discursiva que deve fazer dos diferentes estratos populacionais afro-descendentes - do ponto de vista social e cultural tão diversos entre si - um coletivo político capaz de enfrentar desigualdades raciais. A ideia de uma raça negra definida politicamente a partir de determinadas características corporais parece responder à impossibilidade fáctica de constituição de uma identidade propriamente étnica para o conjunto de afrodescendentes... (p.|50-|5|)

Ainda segundo o autor, com a retomada do conceito de raça pelo movimento negro nos finais dos anos 1970, teria ocorrido "uma inversão semântica fundamental na categoria usada historicamente para subjugar negros e outros não brancos" (p.|5|).

$\mathrm{Na}$ área da educação, parece que o sinal mais palpável dessa virada está no número especial Raça negra e educação, da revista Cadernos de Pesquisa, de novembro de 1987, organizado por Fúlvia Rosemberg e Regina Pahim Pinto, autoras de reconhecida produção sobre o tema.

Para John Rex, o termo raça, "corretamente usado em sentido científico, é um termo taxonômico de limitada utilidade" (Rex, 1996, p.639). Quanto à etnicidade, o autor entende que se trata de "uma das principais características socialmente relevantes dos seres humanos”, cuja compreensão impõe conside- 
rar a forma como ela se distingue de raça, classe, status e posição, e também como interage com estes na formação de grupos e sistemas sociais (p.282). Ainda segundo o autor, "as raças são grupos bem mais amplos e os grupos étnicos implicam diferenças sutis de comportamento, de forma que dentro de qualquer uma das principais raças ou sub-raças do mundo pode haver grande número de diferenças étnicas internas." (p.283)

Quanto a classe social, a coisa não é menos complicada. Se Joan W. Scott (200 I) pôde falar de "La querelle des femmes" [A querela das mulheres] no final do século XX", em sua luta pela paridade na França, seria irrealista falar de querela das classes sociais nesse mesmo período. Com efeito, à queda do Muro de Berlin e à derrocada da União Soviética, seguiu-se uma situação que pode ser definida como de pensamento único, neoliberal, que chegou a varrer das livrarias as obras de Marx e sobre o marxismo e, com elas, o próprio conceito marxiano de classes sociais, que muitos têm, hoje, como coisa superada. Mesmo assim, alguns autores e autoras, como se viu, reconhecem e acentuam a necessidade de articular, na pesquisa em educação, a perspectiva de classe social com as de gênero e de raça.

Apenas referida neste trabalho, a perspectiva de classe merecerá toda a atenção na continuidade da pesquisa. A análise volta-se, aqui, unicamente para a relação cruzada das variáveis sexo e cor/raça com escolarização.

\section{UM EXPERIMENTO COM BASE NOS MICRODADOS DO CENSO 2000}

O experimento cujos resultados são apresentados aqui foi desenvolvido com base nos microdados do Censo 2000. O estudo é denominado "experimento" no sentido de experiência, de tentativa, no uso de um artifício metodológico. $O$ tipo de processamento buscado no projeto, com possibilidade de cruzamentos complexos de sexo, cor-raça, classe e região (ou unidades da federação), só pode ser obtido a partir dos microdados dos últimos censos do Censo 2000, neste estudo.

O estudo levou em conta apenas as pessoas de 10 anos ou mais. Limitouse a considerar as categorias compostas: homens brancos, homens negros, mulheres brancas, mulheres negras, entendendo-se por negros/as as pessoas que, no censo, se declararam ou foram declaradas pretas ou pardas. As pessoas de 10 anos ou mais, situadas em qualquer uma dessas quatro categorias de 
sexo e cor/raça, foram distribuídas segundo grupos decenais de idade, como 10 a 19 anos, 20 a 29 anos, e assim por diante, até 80 anos ou mais, tendo sempre como critério de corte o dia $1^{\circ}$ de agosto, que foi o dia de referência para o Censo 2000.

Para efeito da análise pretendida neste estudo, esses grupos foram interpretados como gerações: geração nascida até 3 I de julho de 1920 (equivalente ao grupo de 80 anos ou mais), de $1^{\circ}$ de agosto de 1920 a 31 de julho de 1930 , e assim por diante, até $1^{\circ}$ de agosto de 1980 a 31 de julho de 1990. Optouse pela utilização de um indicador educacional sintético - a média de anos de estudos realizados com aprovação por cada geração de homens brancos, homens negros, mulheres brancas, mulheres negras.

A ideia inicial era considerar, no trabalho, apenas o Estado da Bahia, por ter sido o primeiro centro econômico, político e cultural do país e pelo número e representatividade da sua população negra. Optou-se depois por incluir também o Estado do Rio de Janeiro, que compreende a segunda capital do Brasil (na última parte do período colonial, durante todo o Império e na maior parte da República). Com isso, estaria introduzida no estudo também a perspectiva regional.

O modelo de análise assim construído refere-se, portanto, à população recenseada no ano 2000. Trata-se, como já se disse, de um estudo transversal. A organização da população pesquisada em gerações sucessivas é um artifício para introduzir a dimensão tempo e poder captar as diferentes trajetórias da média de anos de estudo pelas sucessivas gerações de cada um dos quatro grupos populacionais considerados. Visto que na continuidade da pesquisa se buscará introduzir também a variável classe social, é inviável o caminho de trabalhar com uma sucessão de censos, simplesmente porque neles não se procedeu a esse tipo de tabulações. $O$ caminho possível é recorrer ao artifício aqui descrito.

Os gráficos I e 2 referem-se, respectivamente, aos estados da Bahia e do Rio de Janeiro. Dois estados representativos enquanto centros políticos, econômicos e culturais em dois longos períodos que cobrem a maior parte da história do país - a Bahia, tendo na cidade de Salvador a capital até 1763, e o Rio de Janeiro, tendo na cidade de mesmo nome a capital da Colônia, do Império e finalmente da República, de 1763 até 1960.

Em relação ao Estado Rio de Janeiro, o gráfico I evidencia duas situações absolutamente distintas no que se refere à média de anos de estudo concluídos 
com aprovação para as quatro categorias populacionais consideradas: homens brancos, mulheres brancas, homens negros e mulheres negras.

De um lado, constata-se a reprodução continuada da desigualdade educacional que pesa sobre as pessoas negras em relação às pessoas brancas, sejam elas homens ou mulheres. Em relação à variável cor/raça, o máximo que se pode dizer é que essa desigualdade educacional em desfavor das pessoas negras tende a se atenuar à medida que se passa das gerações mais velhas para as gerações mais novas, mas não a se extinguir. De outro lado, observa-se uma transformação profunda no que se refere à média de anos de estudo de homens e mulheres. Partindo de uma situação de inferioridade das mulheres, tanto na população negra como na branca, as médias femininas de anos de estudo foram se aproximando lentamente das médias masculinas até ultrapassá-las na geração 1960-1970, alargando-se a diferença a favor das mulheres nas gerações seguintes.

\section{GRÁFICO I}

MÉDIA DE ANOS DE ESTUDO POR SEXO E COR/RAÇA, SEGUNDO AS GERAÇÕES (GRUPOS DE IDADE). BAHIA, 2000

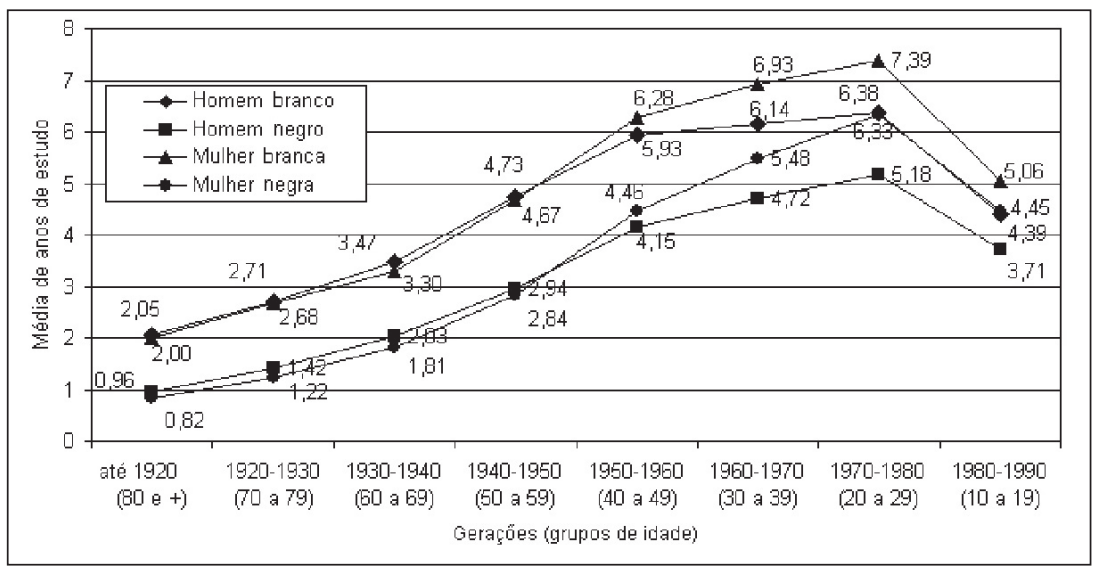

Fonte: Fundação IBGE, 2000.

Em síntese, à medida que se avança das gerações mais velhas para as mais novas, as mulheres, tanto brancas como negras, passam da condição 
de inferioridade em termos de média de anos de estudo para a condição de superioridade. Em outras palavras, vindo respectivamente da segunda e quarta posição na escala hierárquica de anos de estudo nas gerações mais velhas, as mulheres brancas ascendem à primeira posição, superando os homens brancos, enquanto as mulheres negras passam para a terceira posição, superando os homens negros.

Foram de caráter sumamente preconceituoso e discriminatório, no passado nem tão distante, as tentativas de explicar com base nas características físicas ou biológicas da mulher sua condição de inferioridade em relação ao homem (na realidade, de exclusão), em terrenos como o da política, do mercado de trabalho e da escola. Seria incorrer na mesma atitude preconceituosa e discriminatória pretender, agora, encontrar nas diferenças biológicas dos sexos a explicação para a transformação operada no acesso de mulheres e homens à educação escolar. Pelo menos não há nenhuma evidência de alterações nos atributos biológicos dos sexos que possam ser invocados para explicar a mudança verificada nos níveis de escolaridade das mulheres em relação aos homens. É aqui, portanto, que se faz necessário introduzir o gênero como categoria analítica, justamente para significar que a mudança em questão deve ser resultado de transformação ocorrida no plano da cultura, das relações sociais e inclusive das relações de poder entre homens e mulheres.

Pode-se agora proceder à análise dos dados referentes ao Estado da Bahia (Graf. 2) e, comparativamente, ao Estado do Rio de Janeiro (Graf. I). Introduz-se, portanto, na análise a perspectiva regional, ou melhor, das desigualdades regionais.

A primeira revelação é que as trajetórias das médias de anos de estudos, para cada uma das quatro categorias de sexo e cor/raça, verificadas no Estado da Bahia se situam sempre em nível bem inferior àquelas encontradas no Estado do Rio de Janeiro. De outro ângulo, pode-se dizer que, desde as gerações mais velhas até as mais jovens, o nível educacional da população branca, tanto homens como mulheres, do Estado da Bahia, praticamente coincide com o nível educacional da população negra do Rio de Janeiro. Esse fato, ao mesmo tempo em que torna visível a desigualdade entre regiões, realça também a importância de, no estudo da educação no Brasil, se levar em conta a perspectiva regional.

Mas o caso da Bahia apresenta uma particularidade. Ao contrário do verificado no Rio de Janeiro, onde a desigualdade é acentuada, na Bahia, nas 
gerações mais velhas, é muito pequena a vantagem dos homens brancos e homens negros em relação, respectivamente, às mulheres brancas e mulheres negras. Essa situação de quase igualdade das mulheres em relação aos homens de mesma cor/raça nas gerações mais velhas em termos de média de anos de estudo tem um impacto surpreendente nas gerações mais novas. Com efeito, a partir da geração 1970-80, a mulher negra iguala o homem branco quanto à média de anos de estudo, com tendência a ultrapassá-lo.

\section{GRÁFICO 2}

MÉDIA DE ANOS DE ESTUDO POR SEXO E COR/RAÇA, SEGUNDO AS GERAÇÕES (GRUPOS DE IDADE). RIO DE JANEIRO, 2000

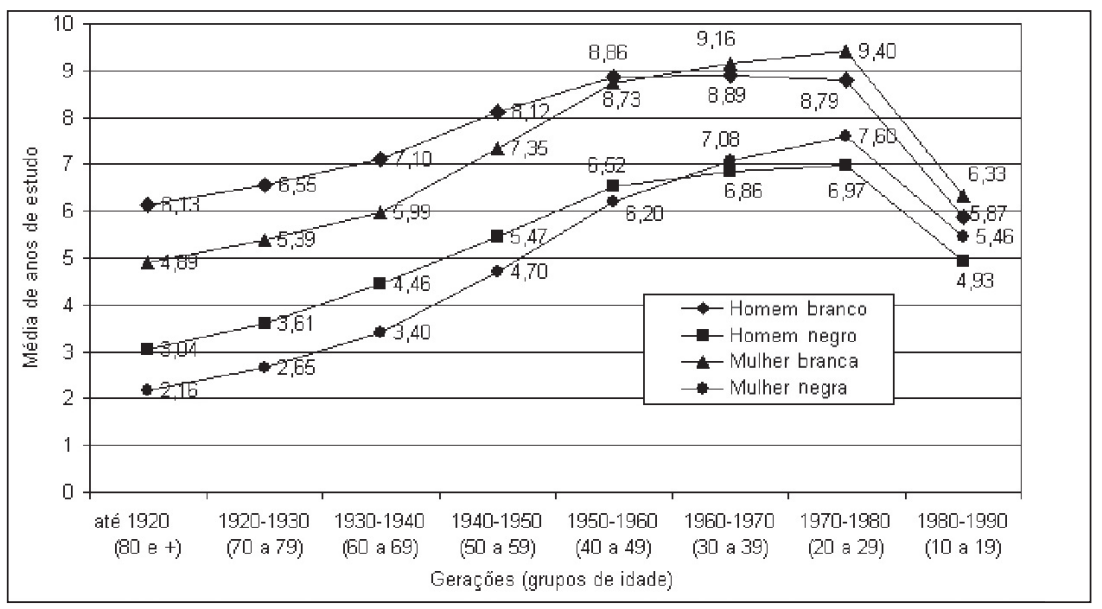

Fonte: Fundação IBGE, 2000.

Nos dois estados, é acentuada a amplitude entre os níveis mínimo e máximo verificados nas gerações mais velhas, variando a média de anos de estudo de aproximadamente 2 a 6 anos no Rio de Janeiro e de I a 2 anos na Bahia.

Se analisados os dois gráficos na perspectiva da relação de cor/raça com a média de anos de estudo, a desigualdade entre brancos/as e negros/as é acentuada nos dois estados. Se analisados os gráficos na perspectivava regional, tanto brancos/as como negros/as do Rio de Janeiro levam grande vantagem em relação, respectivamente, a brancos/as e negros da Bahia. 
Em que pesem as diferenças regionais, o confronto dos dois gráficos permite observar três situações distintas em termos da relação entre as variáveis sexo e média de anos de estudo.

A primeira situação é de superioridade das médias masculinas em relação às femininas em todas as gerações mais velhas - até as gerações nascidas na década 1940-50 na Bahia e na década de 1950-1960 no Rio de Janeiro -, mas com uma diferença regional marcante. Na Bahia, nessas gerações mais velhas, as médias de anos de estudo das mulheres estão muito próximas daquelas dos homens, de modo que a desigualdade aparece como apenas de cor/raça (entre negros/as e brancos/as). Já no Rio de Janeiro, em todas as gerações mais velhas, há uma predominância nítida tanto dos homens em relação às mulheres, quanto das pessoas de cor/raça branca em relação às de cor/raça negra.

A segunda situação é marcada pelo momento em que as médias de anos de estudo das mulheres se igualam às dos homens, o que se manifesta, na Bahia, na geração 1940-1950, e no Rio de Janeiro, entre as gerações 1950 1960 e 1960- 1970. Esse relativo atraso do Rio de Janeiro é compreensível: a desigualdade a ser vencida nesse estado era bem maior do que na Bahia. No entanto, é preciso ter presente que esta segunda situação não é mais do que o ponto de cruzamento das curvas: o ponto de passagem da primeira situação para a terceira.

A terceira situação é dada pela inversão histórica na relação entre sexo e média de anos de estudo. Na Bahia, a superioridade das médias de anos de estudo das mulheres em relação às dos homens manifesta-se já na geração 1950-1960, acentuando-se a partir daí a tal ponto que a nítida hierarquização na ordem mulher branca - homem branco - mulher negra - homem negro, verificada na geração 1960-1970, fica logo reduzida a três níveis, pois a média de anos de estudo da mulher negra alcança a média do homem branco nas gerações 1970-1980 e 1980-1990. No Rio de Janeiro, por conta provavelmente da maior desigualdade entre os sexos nas gerações mais velhas, a progressão é mais lenta: a inversão só aparece de forma acentuada a partir da geração 1970-80.

\section{AVANÇANDO UMA HIPÓTESE DE PESQUISA}

Tais resultados permitem destacar alguns pontos importantes. Em primeiro lugar, eles evidenciam a reprodução, persistente através das sucessivas 
gerações, das desigualdades regionais quanto à escolarização da população brasileira. Não esclarecem, no entanto, a gênese dessas desigualdades', questão que ultrapassa os limites deste trabalho.

Em segundo lugar, os resultados do experimento confirmam, para ambos os sexos e os dois estados pesquisados, a reprodução, também persistente através das sucessivas gerações, das desigualdades em desfavor da população negra em relação à população branca no que se refere à educação escolar.

Em terceiro lugar, tanto na Bahia como no Rio de Janeiro, e tanto entre pessoas negras como entre pessoas brancas, os resultados do estudo evidenciam uma mudança profunda nas relações entre gênero e educação no Brasil. Há clareza quanto à vantagem masculina no passado e quanto à vantagem feminina no presente. A questão está em se conseguir traçar no tempo a trajetória dessa inversão e definir o momento histórico dessa ultrapassagem.

Este é o objetivo principal da pesquisa: descrever o movimento que levou as mulheres da condição de inferioridade à de superioridade em relação aos homens em termos de educação escolar, tanto entre a população branca como entre a população negra e em ambos os estados pesquisados. Suspeitase que, mesmo em acentuada desvantagem relativa no passado, o movimento ascensional diferenciado das mulheres em busca de escolarização remonte ao período imperial, pelo menos ao Segundo Império, de 1840 a 1889.

Outra questão, intimamente relacionada à anterior, que se pretende abordar neste trabalho, assim como no projeto de pesquisa, se refere ao próprio pressuposto básico daquilo que a literatura internacional, e também nacional, qualifica "fracasso dos meninos" (Ferraro, 2009). Esse pressuposto requer um exame atento, à luz justamente das trajetórias de longo prazo da relação entre gênero e escolarização, com atenção também para a interferência das variáveis cor/raça, classe social e região.

Trabalha-se com a hipótese de que o que faz a diferença em favor das mulheres em termos de educação escolar no Brasil é o impulso diferenciado mais vigoroso que de longa data vem distinguindo o movimento das mulheres em busca de escolarização, e que no longo prazo produziu os efeitos que só mais tarde foram identificados e que hoje surpreendem.

I. Sobre isto, pode-se consultar estudo recente de Ferraro e Kreidlow (2004). 
Entende-se que a verificação dessa hipótese está na dependência de se conseguir superar a dicotomia, ou mesmo oposição, entre métodos quantitativos e métodos qualitativos. Em outras palavras, de se conseguir articular, sempre na perspectiva de longo prazo, recursos metodológicos tanto quantitativos como qualitativos. Os parágrafos a seguir oferecem uma primeira amostra dessa utilização combinada de fontes quantitativas e qualitativas.

\section{EXPLORANDO O CAMINHO}

Em estudo sobre os usos da alfabetização no início da Itália moderna, Peter Burke lembra que, na época, a maioria dos italianos "deve ter sido analfabeta - alguns profissionais, a maioria dos camponeses e quase todas as mulheres" (Burke, 1995, p.35). Sobre as exceções à regra no que se refere às mulheres, o autor lembra um fato interessante: "De qualquer forma sabemos que algumas meninas iam à escola. Villani refere-se a 'meninos e meninas' aprendendo a ler na Florença do século XIV, e é uma pena que esse amante das estatísticas não nos dê uma ideia das percentagens correspondentes" (Burke, p.36).

A propósito, seis séculos mais tarde, essa falha do "amante das estatísticas" seria, de certa forma, suprida no Brasil pelo poeta mineiro Carlos Drummond de Andrade, nascido em Itabira em 1902. Mas, aqui, é necessário esclarecer porque se ousa recorrer ao testemunho de um poeta, quando, decorrido tão pouco tempo das comemorações do quarto centenário, em 2005, da famosa obra Don Quijote de la Mancha [Dom Quixote de la Mancha], alguns - ou muitos - devem ter ainda viva na memória a desconfiança da sobrinha do Cavaleiro da Triste Figura em relação aos poetas e à poesia. Com efeito, a sobrinha defendeu com empenho, perante o cura e o barbeiro, que, junto com os livros sobre cavalaria andante, que haviam transtornado o juízo do tio, fossem lançados ao fogo também os livros de poesia, sob o argumento de que, segundo se dizia, o tornar-se poeta era "enfermidade incurável e contagiosa":

Ah, senhor! - exclamou a sobrinha - bem poderia vosmecê mandar queimá-los com os demais, pois não me surpreenderia se ao meu tio, uma vez curado da enfermidade cavaleiresca e lendo esses livros, lhe desse na telha fazer-se pastor e meter-se pelos bosques e prados, cantando e tocando, ou (o que seria pior) fazer-se poeta, o que, segundo dizem, é doença incurável e contagiosa. (Cervantes, 1988, v. I, p.71-72). 
Que socorro, então, esperar de um poeta, especialmente em assunto de estatística? Para responder, só lhe dando a palavra.

No poema "Classe mista", Carlos Drummond de Andrade (2002, p. l.023) devia estar lembrando cena cotidiana na escola de sua infância, lá por volta de 1910:

\section{Classe mista}

"Meninas, meninas,

do lado de lá.

Meninos, meninos,

do lado de cá."

Por que sempre dois lados,

corredor no meio,

professora em frente,

e o sonho de um tremor de terra

que só acontece em Messina,

jamais, jamais em Minas,

para, entre escombros, me ver

junto de Conceição até o fim do curso?

Meninas - meninos, lado de lá - lado de cá, dois lados, corredor no meio, professora em frente! Tudo sugere uma classe de ensino primário "mista", com participação equilibrada, senão igual, de meninos e meninas, embora dividida em dois lados. Isto em Minas Gerais, no início do século XX. Nesse estado, nos censos de 1872 e 1890, a taxa de analfabetismo entre as pessoas de 5 anos ou mais era de aproximadamente $88 \%$, figurando entre as mais elevadas no país. Considerando que no censo de 1920 chegaria a 75,4\%, pode-se estimar que, em 1910, deveria estar por volta de 80\%. Nessas condições, qual a plausibilidade da situação rememorada pelo poeta?

O rastreamento das estatísticas disponíveis, por mais precárias que sejam, talvez possa esclarecer muito mais coisas do que se pensa. A dar crédito aos dados reunidos por José Ricardo Pires de Almeida ( 1989), em História da instrução pública no Brasil (1 989), a participação das meninas na matrícula total nas escolas primárias públicas no Estado de Minas Gerais, que representava apenas $21 \%$ do total (pouco mais de 1/5) em 1875, elevou-se, em apenas 13 anos, para 34,4\% (mais de I/3), no ano de 1888. Em números absolutos, 
a matrícula das meninas mais que triplicou nesse período, subindo de 4.498 para I 5.1 I I (+336\%), ao passo que a matrícula dos meninos não chegou a duplicar, passando de 16.908 para 28.826 (+70,5\%). Segundo a mesma fonte, no ano de 1889, as meninas representavam nada menos do que 50,4\% da matrícula total na instrução primária (pública e privada) no Município Neutro.

Michelle Perrot (200 I) afirma que, na França, a alfabetização das mulheres progrediu rapidamente nas cidades do século XIX, e que a leitura privada de romances e jornais modelou seu imaginário. Será que se repetiu em Minas (e no Brasil), desde o último terço ou quartel do século XIX, apenas partindo de nível muito mais elevado de analfabetismo, um movimento acelerado de alfabetização das mulheres, semelhante ao descrito por Michelle Perrot em relação à França?

Os dados relativos a Minas Gerais parecem sugerir essa possibilidade. Até na conservadora São Luiz, capital da Província do Maranhão, os jornais e o romance já modelavam, na época, o imaginário das jovens, suscitando o interesse pela alfabetização, pelo menos entre a elite e a classe média. É o que se deduz das palavras que o romancista Aloísio de Azevedo, em sua obra 0 mulato, de 188I, põe na boca da fofoqueira Amância Sousellas:

- No meu tempo - dizia com azedume Amância Sousellas - as meninas tinham a sua tarefa de costura para tantas horas, e haviam de pôr pr'ali o trabalho! Se o acabavam mais cedo, iam descansar? ... Boas! Desmanchavam, minha senhora! Desmanchavam para fazer de novo! E hoje?... - perguntava, dando um pulinho, com as mãos nas ilhargas. - Hoje é o maquiavelismo da máquina de costura! Dá-se uma tarefa grande e é só "zuc-zuc-zuc" e está pronto o serviço! E daí, vai a sirigaita pôr-se de leitura nos jornais, tomar conta do romance ou então vai para a indecência do piano! (Azevedo, 2004, p.7I)

O comentário de Amância Sousellas, que, por sinal, "detestava o progresso" (Azevedo, 2004), ajuda a entender a relação estreita entre a busca de escolarização e outras dimensões e transformações na sociedade, com destaque para as inovações tecnológicas e a luta pelo ingresso no mercado de trabalho, a participação política, o acesso aos bens da cultura etc.

Diferente de Drummond de Andrade, que se ocupava apenas dos meninos, das meninas e da professora de sua classe mista, o também mineiro 
Milton do Nascimento, poeta, compositor e cantor, levanta, a um só tempo, na canção "Morro Velho", gravada originalmente em 1967, a questão da relação de cor/raça, de classe social e inclusive de gênero com escolarização. Seus versos põem em evidência o contraste entre os desiguais destinos dos dois meninos e as desiguais condições objetivas, em termos tanto de cor/raça quanto de classe social, responsáveis por traçar os respectivos destinos. A leitura atenta revela desigualdade inclusive na relação de gênero. A cena que inspirou o poeta-compositor Milton Nascimento deve ser lá de sua infância, em meados do século $X X$ :

\section{Morro velho}

No sertão da minha terra

Filho do sinhô vai embora

Fazenda é o camarada

Tempos de estudo na cidade grande

que ao chão se deu

Fez a obrigação com força

Parte, tem os olhos tristes

Deixando o companheiro

Parece até que tudo aquilo ali é seu

na estação distante

Poder sentar no morro

E ver tudo verdinho, lindo a crescer

'Não me esqueça, amigo,

Orgulhoso camarada

De viola em vez de enxada

eu vou voltar'

Some longe o trenzinho

Filho de branco e do preto

ao Deus dará

Correndo pela estrada

Quando volta já é outro

atrás de passarinho

Trouxe até sinhá-mocinha

para apresentar

Pela plantação adentro

Linda como a luz da lua

Crescendo os dois meninos,

Que em lugar nenhum sempre pequeninos

brilha como lá

$[\ldots]$

Já tem nome de doutor

E agora na fazenda

é quem vai mandar

E seu velho camarada

Já não brinca, mas trabalha.

A propósito, basta lembrar a riqueza dos termos ou dimensões que o poeta-compositor conseguiu reunir na letra de uma única canção. Nas pa- 
lavras "filho de branco e do preto" se expressa claramente a dimensão cor/ raça. Estreitamente ligada a ela, está a dimensão classe social, que se manifesta em expressões como "de viola em vez de enxada", "filho do sinhô", "e agora na fazenda é quem vai mandar". Por sua vez, o seu velho camarada "já não brinca, mas trabalha".

É a ação conjunta da dupla relação fortemente intrincada - de cor/raça e de classe social - que vai definir também o futuro dos dois meninos no que se refere à escola: para um, "tempos de estudo na cidade grande", de onde retornará com "nome de doutor"; para o outro, em vez de estudo, a enxada, o trabalho, ser mandado. A relação de gênero está também presente na canção, embora de forma mais velada ou mais sutil. Uma relação de superioridade e dominação do "filho do sinhô", agora com nome de doutor, que retorna para mandar e que traz consigo, da cidade grande, entre outras tantas coisas suas, "até sinhá-mocinha para apresentar".

Em tempo. Para o velho camarada, que ficou "na estação distante" e que foi posto ainda criança a trabalhar, a questão de uma companheira sequer se coloca!

\section{A TÍTULO DE CONCLUSÃO}

A relação entre classe social e escolarização, tão bem colocada por Milton Nascimento, não fez parte do quadro de relações exploradas neste trabalho. Fica, portanto, como desafio na continuidade da pesquisa. Pois o destino tão desigual dos dois meninos - do "filho de branco e do preto" - no que se refere à escola, mantém, no Brasil, toda a sua atualidade, como revelaram os dados examinados do Censo 2000.

E não só no Brasil. Neste início do século XXI, situação muito semelhante pode ser encontrada no romance de The kite runner (2003), de Khaled Hosseini, traduzido e publicado no Brasil sob o título de O caçador de pipas. Como os dois meninos de "Morro velho", também em Cabul "Baba e Ali cresceram juntos, como companheiros de brincadeiras [...] exatamente como Hassan e eu [Amir] cresceríamos juntos uma geração mais tarde. [...] Em nenhuma dessas histórias [travessuras], porém, baba se referia a Ali como amigo" (Hosseini, 2005, p.32). E prossegue o autor: "O curioso é que também nunca pensei em Hassan e eu como amigos. Pelo menos não no sentido habitual". E esclarece: 
"Porque não é fácil superar a história. Tampouco a religião. Afinal de contas, eu era pashtun, e ele, hazara; eu era sunita, e ele, xiita, e nada conseguiria modificar isso. Nada."

Apesar de terem passado doze anos brincando juntos, o destino dos dois meninos de Cabul quanto à escola é muito parecido com o dos meninos de Morro Velho. "Durante o ano letivo - diz o autor - tínhamos uma rotina diária". Qual? Enquanto Amir resistia a levantar e reclamava do dever de casa, para depois do café seguir até a escola no Ford Mustang preto do pai, Hassan, que já se havia levantado mais cedo, orado com o pai Ali, ajudado a preparar o café da manhã e arrumado o quarto de Amir, "ficava em casa e ajudava ali nas tarefas diárias: lavar à mão toda a roupa suja e estendê-la no quintal para secar, varrer a casa, ir ao bazaar para comprar naan fresco, marinar a carne para o jantar, regar o gramado" (p.34).

Depois da aula, os dois meninos pegavam um livro e corriam para a colina. Ali, à sombra de um pé de romã, Amir lia histórias que o companheiro "não podia ler sozinho". "Pois Hassan [prossegue o autor num tom fortemente determinista] cresceria analfabeto como a maioria dos hazaras: isto já estava decidido desde o minuto em que nasceu, até mesmo desde o instante em que foi concebido no útero nada receptivo de Sanaubar - afinal, para que um criado precisaria da palavra escrita?" (p.34-35).

Quanto à relação entre gênero e escolarização, talvez fosse muito cedo para que Milton Nascimento pudesse, em 1967, quando da composição de "Morro velho", captar a transformação que mal começava a ser identificada nos grupos populacionais mais jovens e que só se manifestaria com força mais pelo final do século $X X$.

Estudo da Unesco de 1953 identificara, com base no Censo 1940, taxas masculina e feminina de analfabetismo praticamente idênticas na faixa de 10 a 19 anos (57,3\% e 57,4\%, respectivamente), o que sugeria uma equiparação ou igualdade entre os sexos nessa faixa de idade. A novidade estaria na igualdade atingida pelas mulheres, nessa faixa de idade, contra a histórica desigualdade evidenciada em todos os demais grupos de idade, a partir do de 20 a 24 anos.

agrupamento feito nesse estudo (pessoas de 10 a 19 anos) levou, no entanto, a uma interpretação equivocada da mudança. $\bigcirc$ que se delineava nos grupos de idade mais jovens não era a equiparação das meninas aos meninos, mas uma desigualdade invertida, agora a favor das meninas em relação aos meninos quanto à alfabetização. Foi o Conselho Nacional da Estatística - CNE -, que 
identificou esse início de inversão na relação entre gênero e alfabetização já no começo dos anos 1960: "Tanto em 1940 como em 1950, nos grupos de 5 a 9 e 10 a 14 anos verificava-se uma inferioridade dos meninos em relação às meninas quanto à alfabetização, desvantagem esta que, no censo de 1950, se estendeu também para a faixa de 15 a 19 anos" (Fundação IBGE, |96।, p.389).

Em síntese, e para terminar, foi o Censo 1940 que identificou pela primeira vez nos grupos populacionais mais jovens (de 5 a 9 e 10 a 14 anos) o começo da situação que hoje se estende para a maioria da população brasileira, do grupo de 5 a 9 até o de 40 a 44 ou 45 a 49 anos, dependendo do indicador: índices educacionais mais elevados entre as mulheres do que entre os homens.

Pensamos que um dos grandes desafios para a pesquisa hoje é captar o significado e o alcance prático dessa transformação no domínio da educação escolar em termos de superação da histórica desigualdade e discriminação social da mulher.

\section{REFERÊNCIAS BIBLIOGRÁFICAS}

ALMEIDA, J. R. P. de. História da instrução pública no Brasil ( 1500 - | 889): história e legislação. São Paulo: Educ; Brasília: Inep, 1989.

ANDRADE, C. D. de. Poesia completa. Rio de Janeiro: Nova Aguilar, 2002. Classe mista, p. I.023. (Centenário Drummond)

APPLE, M. W. Relações de classe e de gênero no processo do trabalho docente. Cadernos de Pesquisa, São Paulo, n. 60, p.3-14, fev. 1987.

ATHAYDE, P. de. Luta secular. Carta Capital, v. I2, n. 396, p. I 2-16, 7 jun. 2006.

AZEVEDO, A. O Mulato. São Paulo: Martin Claret, 2004. (Col. A obra-prima de cada autor) BLACK, E. A Guerra contra os fracos: a eugenia e a campanha dos Estados Unidos para criar uma raça dominante. São Paulo: A Girafa, 2003.

BURKE, P. Os usos da alfabetização no início da Itália moderna. In: BURKE, P.; PORTER, R. (orgs.) História social da linguagem. São Paulo: Edunesp, 1997. p. I5-4I

CALDWEL, K. L. Fronteiras da diferença: raça e mulher no Brasil. Estudos Feministas, v. 8, n. 2, p.91-I08, 2. sem. 2002.

CARVALHO, M. P. de. A História de Aida: ensino, classe, raça e gênero. Educação e Pesquisa, São Paulo, v. 25, n. I, p.89-106, jan.jjun. 1999. 
Quem são os meninos que fracassam na escola? Cadernos de pesquisa, São Paulo, v. 34, n. 12 I, p. II-40, jan./abr. 2004.

CERVANTES, M. de. Dom Quixote. São Paulo: Publifolha, 1998. (Trad. Almir de Andrade, Milton Amado)

CHRISTIE, P., GORDON, A. Politics, poverty and education in rural South Africa. British Journal of Sociology of Education, v. I3, n.4, p.399-418, 1992.

COSTA, S. A Mestiçagem e os seus contrários: etnicidade e nacionalidade no Brasil contemporâneo. Tempo Social, v. I3, n. I, p. |43- I58, maio 2001 .

ENGUITA, M. Os Desiguais resultados das políticas igualitárias: classe, gênero e etnia na educação. Revista Brasileira de Educação, n.3, p.5-17, set./dez. 1996.

FERRARO, A. R. Gênero e alfabetização no Brasil. Didáticas Especiais. Madrid, v. 0, p. I - I7, 2009.

FERRARO, A. R.; KREIDLOW, D. Analfabetismo no Brasil: configuração e gênese das desigualdades regionais. Educação e Realidade, Porto Alegre, v.29, n. I , p. I 79-200, jul./dez. 2004.

FUNDAÇÃO IBGE. Conselho Nacional de Estatística. Censo demográfico 2000: microdados. Rio de Janeiro, 2000. DVD Censo demográfico 1940. Rio de Janeiro, 1940. . Censo demográfico 1950. Rio de Janeiro, 1950.

.Contribuições para o estudo da demografia no Brasil. Rio de Janeiro, 1961. Alfabetização, parte G, p.387-448.

GOBINEAU, A. de. Essays sur l'inegalité des races humaines. In : GAULTIER, J. Fuvres, I. Paris: Gallimard, 1983. p. |33-1515.

GUMPLOWICZ, L. La Lucha de razas. Buenos Aires: Fas, 1944.

HASENBALG, C. Entre o mito e os fatos: racismo e relações raciais no Brasil. Dado: Revista de Ciências Sociais, Rio de Janeiro, v.38, n.2, p.355-374, 1995.

HOSSEINI, K. O Caçador de pipas. Rio de Janeiro: Nova Fronteira, 2005.

NASCIMENTO, M. Travessia, 2002. Morro velho. [disco compacto reproduzido do original de 1987]

NICHOLSON, L. Interpretando o gênero. Estudos Feministas, v. 8, n.2, p.91-108, 2000.

OUTHWAITE, W.; BOTTOMORE, T. Dicionário do pensamento social do século XX. Rio de Janeiro: Jorge Zahar, 1996. 
PERROT, M. Os Excluídos da história: operários, mulheres e prisioneiros. 3.ed. Rio de Janeiro: Paz e Terra, 2001.

REAY, D. Intersections of gender, race and class in the primary school. British Journal of Sociology of Education, v.12, n.2, p.163-182, 1991.

REX, J. Etnicidade . In: OUTHWAITE, W.; BOTTOMORE, T. Dicionário do pensamento social do século XX. Rio de Janeiro: Jorge Zahar, 1996. p.282-284.

Raça. In: OUTHWAITE, W.; BOTTOMORE, T. Dicionário do pensamento social do século XX. Rio de Janeiro: Jorge Zahar, 1996. p.637-639.

ROSEMBERG, F. Analfabetismo, raça e gênero nos censos demográficos. São Paulo, nov. 1993. Educação infantil, classe, raça e gênero. Cadernos de Pesquisa, São Paulo, v.96, p 58-65, fev. 1996.

ROSEMBERG, F; PIZA, E. Analfabetismo, gênero e raça no Brasil. Revista USP, São Paulo, n. 28, p. I10-121, dez.1995/fev. 1996.

SCOTT, J. "La querelle des femmes" no final do século $X X$. Estudos Feministas, v.2. n.9, p.367-388, fev. 200I.

UNESCO. L'Analphabétisme dans divers pays: étude statistique préliminaire sur la base des recensements effectués depuis 1900. Paris, 1953.

WALBY, S. Gênero. In: OUTHWAITE, W.; BOTTOMORE, T. Dicionário do pensamento social no século XX. Rio de Janeiro: Jorge Zahar, 1996. p.332-335.

Recebido em: fevereiro 2008

Aprovado para publicação em: abril 2008 